(2) Open Access Full Text Article

\title{
Comparison of the long-term efficacy and safety of generic tacrolimus, Tacrobell, with Prograf in liver transplant recipients
}

This article was published in the following Dove Press journal:

Drug Design, Development and Therapy

\section{Ho Joong Choi \\ Dong Goo Kim \\ Bong Jun Kwak \\ Jae Hyun Han \\ Tae Ho Hong \\ Young Kyoung You}

Department of Surgery, Seoul St Mary's Hospital, College of Medicine, The Catholic University of Korea, Seoul, Republic of Korea

Correspondence: Dong Goo Kim Division of Hepatobiliary-Pancreas Surgery and Liver Transplantation, Department of Surgery, Seoul St Mary's Hospital, College of Medicine, The Catholic University of Korea, 222,

Banpo-daero, Seocho-gu, Seoul, 0659I, Republic of Korea

Tel +82222586102

Fax +82 25952992

Email kimdg@catholic.ac.kr
Introduction: The purpose of this study was to compare the safety and efficacy of generic tacrolimus (Tacrobell [TCB]) and a reference tacrolimus (Prograf [PGF]) in liver transplant recipients.

Patients and methods: We retrospectively analyzed 167 patients who used TCB or PGF between January 2009 and March 2016 for $>1$ year (TCB group, $n=86$; PGF group, $n=81$ ). To assess the efficacy and safety of TCB, we evaluated the relationship between drug dose and trough level, survival, rejection, infection, kidney function, and side effects.

Results: There was no difference in the preoperative demographics between the two groups. Moreover, there was no difference in the drug dose and trough level between the groups at 1 week after surgery. Coefficient of variation $(\mathrm{CV})$ values were obtained at the drug trough level for each patient and no differences in CV values were identified within 1 year $(p=0.587)$ and up to 5 years $(p=0.824)$ in both groups. Rehospitalization $(p=0.1)$ and total rejection $(p=0.915)$ did not differ between the two groups, but the rejection severity, recorded as the rejection activity index value, was worse in the PGF group $(p=0.039)$. No difference was found in the infection rate $(p=0.818$ ), and with regard to nephrotoxicity, there was no difference in the rate of patients with chronic kidney disease stage 3 and above during the follow-up period. No differences were found between the two groups in terms of drug side effects and adverse events.

Conclusion: The generic tacrolimus, TCB, is a comparable alternative to the original tacrolimus, PGF, as a main immunosuppressive drug for liver transplantation.

Keywords: liver transplantation, generic tacrolimus, Tacrobell, Prograf

\section{Introduction}

Tacrolimus is an effective immunosuppressant and its use is well established in solid organ transplantation. ${ }^{1}$ Tacrolimus acts as an immunomodulatory agent by blocking the transcription of the gene encoding interleukin-2 (IL-2) that is essential for the T-cell-mediated immune response. ${ }^{2,3}$ As in other organ transplants, a variety of immunosuppressants have been used in combination in liver transplantation (LT). Among these immunosuppressive agents, tacrolimus is the most importantly used medication in LT.

Most countries have attempted to reduce the cost of transplant patient care, but the financial burdens of immunosuppressive therapy remain high. ${ }^{4}$ Generally, generic drugs have a cost-saving effect. Minimizing drug costs is an important component in maintaining comprehensive and equitable health care. ${ }^{4}$ For this reason, the development and use of generic tacrolimus is essential. Generic tacrolimus has met all the standards for demonstrating bioequivalence and is therapeutically equivalent 
to the reference tacrolimus, Prograf (PGF; Astellas Pharma Inc., Tokyo, Japan). ${ }^{5}$ Tacrobell (TCB; Chong Kun Dang Pharmaceutical Corp, Seoul, Korea) is a generic formulation of tacrolimus that was approved in 2004 by the Korea Ministry of Food and Drug Safety. ${ }^{6}$

The purpose of this study was to evaluate the long-term efficacy and safety of generic tacrolimus, TCB, compared to PGF in liver transplant recipients. We retrospectively reviewed $\sim 5$ years of data concerning patients who were treated with TCB or PGF.

\section{Patients and methods}

The present retrospective observational study was approved by the institutional review board of Catholic Medical Center, the Catholic University of Korea (approval no KC16RISI1029); the process of patient consent was waived because this study was a retrospective study of data from the medical records. Records that identified the subject of the study were kept confidential.

From January 2009 to March 2016, 499 adult patients underwent LT at our institution. Among them, 167 patients who used TCB or PGF for $>1$ year were included in this retrospective analysis. This study was designed for patients who had been using TCB or PGF for $>1$ year during a 7-year period (from January 2009 to March 2016), especially those who were followed up by a single surgeon for a more objective analysis. Of the 499 patients, 167 patients who underwent surgery and follow-up by one surgeon were selected to eliminate bias. TCB had been in use since January 2009, so our study period commenced from January 2009. The drugs used in the TCB and PGF groups were administered alternately for each patient, with no switch between TCB and PGF. There were no patients using TCB and PGF at the same time, and tacrolimus was discontinued and switched to mycophenolate mofetil (MMF) monotherapy or mechanistic target of rapamycin inhibitor. The TCB group included 86 patients and the PGF group included 81 patients. The mean follow-up duration was $53.0 \pm 25.52$ months.

To determine the efficacy of TCB, we investigated the relationship between the drug dose and trough level of the drug, coefficient of variation (CV) values, mortality, survival, and rejection. $\mathrm{CV}$ values were obtained at the drug trough level for each patient to evaluate the intra-patient variability of tacrolimus and were compared between the two groups. $\mathrm{CV}$ was calculated according to the following equation: $\mathrm{CV}(\%)=(\sigma / \mu) \times 100(\sigma=$ standard deviation and $\mu=$ mean of the tacrolimus trough level). To investigate the safety of $\mathrm{TCB}$, we reviewed the rate of rehospitalization, infection, kidney function (serum creatinine and glomerular filtration rate [GFR]), hypertension, metabolic disorder (diabetes and hypercholesterolemia), de novo malignancy, and drug side effects. We divided rejection into "biopsy proven" and "clinical" categories. Based on the Banff schema, ${ }^{7}$ biopsy proven rejection defines mild rejection as $2 \sim 3$ points of the rejection activity index (RAI) and moderate rejection as $\geq 4$ points. Patients who did not undergo biopsy but who had serum alanine aminotransferase $($ ALT) $>200 \mathrm{IU} / \mathrm{L}$ or total bilirubin $>3 \mathrm{mg} / \mathrm{dL}$ without biliary complication were defined as clinical suspicion of rejection. There were no exact criteria for biopsy. In patients with elevated liver enzyme, biopsy was performed if there was no improvement after conservative treatment. The same criteria were applied to both groups. Two groups of liver transplant patients were divided according to the chronic kidney disease (CKD) stages, and CKD stage 3 or higher (GFR $<60 \mathrm{~mL} / \mathrm{min} / 1.73 \mathrm{~m}^{2}$ ) was defined as renal dysfunction. No patient underwent simultaneous liver-kidney transplantation. Patients with hypertension (systolic $>140 \mathrm{mmHg}$ or diastolic $>90 \mathrm{mmHg}$ ), diabetes (fasting blood sugar $\geq 126 \mathrm{mg} / \mathrm{dL}$ ), and hypercholesterolemia (total cholesterol $>200 \mathrm{mg} / \mathrm{dL}$ or high density lipoprotein cholesterol $<40 \mathrm{mg} / \mathrm{dL}$ ) were defined as having met the diagnostic criteria for the disease or were treated with medications.

Immunosuppressive treatment included a regimen featuring tacrolimus (TCB or PGF) as a component of a double- or triple-drug cocktail (the other two drugs were prednisone and MMF). The initial dose of tacrolimus was $1 \mathrm{mg}$ and was adjusted daily by checking the trough levels. An IL-2 receptor blocker was administered on the day of the operation and on the fourth postoperative day. Steroids were withdrawn 1 month after surgery, and MMF was withdrawn 6 months after surgery. The immunosuppressive protocol did not differ between the two groups.

\section{Statistical analysis}

Numerical data are presented as means with standard deviations. Continuous variables (means, standard deviations, medians, and ranges) were analyzed using the independent $t$-test or the chi-squared test, and proportions were compared using Pearson's chi-squared and Fisher's exact tests. Overall survival and rejection-free survival (RFS) rates were estimated using the Kaplan-Meier method and survival curves were compared with the aid of the log-rank test. All statistical analyses were performed using the SPSS software (version 19.0; IBM Corporation, Armonk, NY, USA). $p$-values $<0.05$ were considered to indicate statistical significance. 


\section{Results}

\section{Patient demographics}

A total of 167 patients who underwent LT up to March 2016 were reviewed. The TCB $(\mathrm{n}=86)$ and PGF $(\mathrm{n}=81)$ groups were compared according to their demographics and characteristics. During the observation period, 25 patients (29.1\%) in the TCB group and 12 patients (14.8\%) in the PGF group discontinued medication or switched to other drugs, and this difference was significant $(p=0.027)$. The most common cause of drug change or interruption was nephrotoxicity in both groups; however, there was no significant difference between nine of these patients $(10.5 \%)$ in the TCB group and five of these patients $(6.2 \%)$ in the PGF group $(p=0.391)$. There was no significant cause of drug change other than nephrotoxicity. We compared age, sex, body mass index, cause of liver disease, prevalence of hepatocellular carcinoma, Child-Pugh score, model for end-stage liver disease score, ratio of living donor living transplantation, preoperative creatinine, estimated GFR, CKD stage, ALT, total bilirubin, prevalence of preoperative diabetes, hypertension, and hypercholesterolemia, and mean follow-up duration. No differences were identified between the two groups (Table 1).

Table I Comparison of the demographics and characteristics between the TCB and PGF groups

\begin{tabular}{|c|c|c|c|}
\hline & TCB $(n=86)$ & PGF $(n=8 I)$ & $p$-value \\
\hline Age (years) & $51.64 \pm 8.76$ & $51.94 \pm 8.25$ & 0.821 \\
\hline Male & $56(65 \%)$ & $58(72 \%)$ & 0.368 \\
\hline Body mass index & $24.30 \pm 3.37$ & $25.35 \pm 3.84$ & $0.06 \mathrm{I}$ \\
\hline HBV:HCV:alcoholic:others & 47 (55\%):6:19:14 & $5 \mid(63 \%): 3: 17: 10$ & 0.616 \\
\hline Hepatocellular carcinoma & $29(33.7 \%)$ & $37(45.7 \%)$ & 0.114 \\
\hline Child-Pugh score & $9.14 \pm 2.83$ & $9.23 \pm 2.92$ & 0.831 \\
\hline MELD score & $16.58 \pm \mid 1.07$ & $17.89 \pm 1 \mid .76$ & 0.460 \\
\hline LDLT & 73 (84.9\%) & $64(79.0 \%)$ & 0.323 \\
\hline Creatinine, $\mathrm{mg} / \mathrm{dL}$ & $1.34 \pm 2.33$ & $1.13 \pm 0.95$ & 0.436 \\
\hline eGFR (mL/min/l.73 m²) & $94.19 \pm 45.75$ & $92.61 \pm 39.67$ & 0.812 \\
\hline CKD stage (I:2:3:4:5) & $48: 22: 8: 5: 3$ & $47: 13: 17: 2: 2$ & 0.141 \\
\hline Alanine transferase (U/L) & $189.38 \pm 594.42$ & $231.68 \pm 865.05$ & 0.712 \\
\hline Total bilirubin (mg/dL) & $7.61 \pm 11.4$ & $9.35 \pm 13.36$ & 0.365 \\
\hline Blood pressure, $\mathrm{mmHg}$ & $119.40 \pm 16.72$ & $119.53 \pm 17.05$ & 0.959 \\
\hline $\begin{array}{l}\text { Preoperative } \\
\text { hypertension (\%) }\end{array}$ & $12(14.0 \%)$ & $12(14.8 \%)$ & 0.874 \\
\hline Fasting blood sugar, mg/dL & $117.56 \pm 49.19$ & $|25.27 \pm 44.1|$ & 0.289 \\
\hline Preoperative diabetes (\%) & $17(19.8 \%)$ & $23(28.4 \%)$ & 0.192 \\
\hline Mean cholesterol, mg/dL & $130.26 \pm 48.02$ & $116.37 \pm 46.60$ & 0.096 \\
\hline Hypercholesterolemia (\%) & I (I\%) & 0 & 0.330 \\
\hline $\begin{array}{l}\text { Follow-up period } \\
\text { (months) }\end{array}$ & $51.45 \pm 24.25$ & $54.68 \pm 26.85$ & 0.416 \\
\hline
\end{tabular}

Note: Data presented as mean \pm SD unless otherwise indicated. Abbreviations: $\mathrm{HBV}$, hepatitis $B$ virus; $\mathrm{HCV}$, hepatitis $\mathrm{C}$ virus; $L D L T$, living donor liver transplantation; MELD, Model for End-Stage Liver Disease; eGFR, estimated glomerular filtration rate; PGF, Prograf; TCB, Tacrobell; CKD, chronic kidney disease.

\section{Efficacy}

The TCB group tended to use fewer drugs for the first week after transplantation, but thereafter there was no difference in drug dose between the two groups. The blood drug trough level was higher in the TCB group on the third postoperative day. Within 1 week, TCB tended to have higher drug trough levels even with low doses, but there was no difference between the two groups after this time (Figure 1). $\mathrm{CV}$ values were then obtained at the drug trough level for each patient and were compared between the two groups. There were no differences in CV values within the course of 1 year $(p=0.587)$ and up to 5 years $(p=0.824)$ in both groups. There was also no difference between rejection and non-rejection when comparing $\mathrm{CV}$ values according to rejection (Table 2).

Biopsy proven rejection occurred in 15 patients (17.4\%) in the TCB group and 29 patients (29.6\%) in the PGF group, but this difference was not significant $(p=0.063)$. However, a moderate RAI value of four or higher was more common in the PGF group ( $p=0.039)$, and the mean RAI was significantly higher in the PGF group compared to the TCB group $(p=0.048)$. The clinical suspicion of rejection without biopsy (ALT $>200 \mathrm{U} / \mathrm{L}$ or total bilirubin $3 \mathrm{mg} / \mathrm{dL}$, without biliary complication) was significantly higher in the TCB group $(n=13,15.1 \%)$ than in the PGF group $(n=3,3.7 \%)(p=0.012)$. However, there was no significant difference in terms of total rejection (biopsy proven rejection and clinically suspected rejection) between 28 patients (32.6\%) in the TCB group and 27 patients (33.3\%) in the PGF group $(p=0.915)$. In the TCB group, eight patients (9.3\%) underwent steroid pulse therapy for rejection and all of them responded to it. In the PGF group, 14 patients $(17.3 \%)$ underwent steroid pulse therapy, but four patients did not respond; these four patients were treated with antithymocyte globulin (Table 3). We then compared RFS in the TCB and PGF groups according to the total rejection. No significant difference in RFS was detected between the TCB and PGF groups ( $p=0.837$ ) (Figure 2).

\section{Safety}

The rehospitalization rate of the TCB group was $58.1 \%$ and that of the PGF group was $70.4 \%$, but this difference was not significant $(p=0.1)$. The frequency of rehospitalization was subdivided into early rehospitalization (within 30 days) and late rehospitalization (after 30 days). Early rehospitalization and late rehospitalization of the TCB group were $24(48.0 \%)$ and 26 (52.0\%), respectively, and 26 (46.4\%) and $30(53.6 \%)$ for the PGF group which did not differ significantly $(p=0.871)$. The most common cause of readmission 


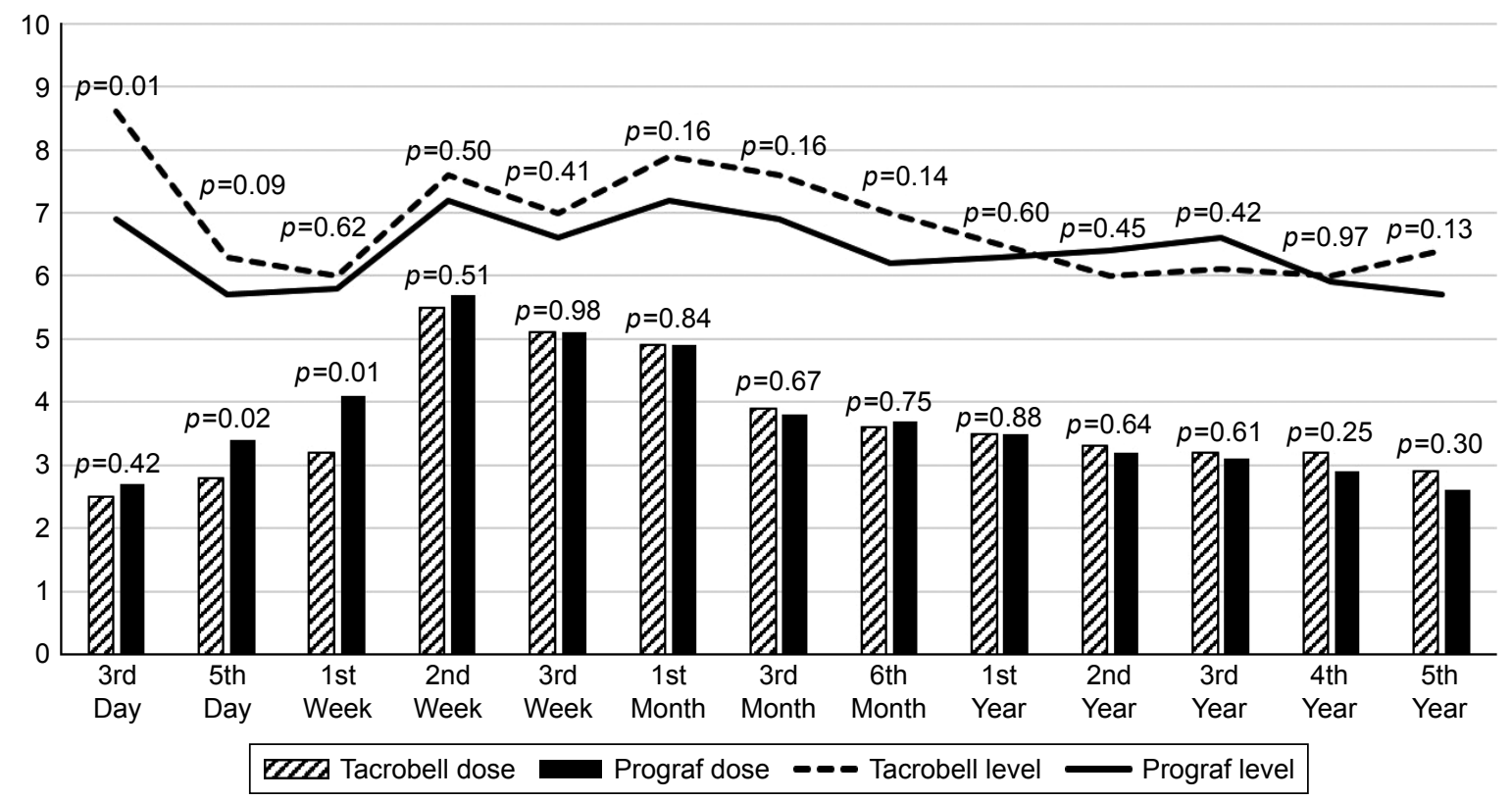

\begin{tabular}{|c|c|c|c|c|c|c|c|c|c|c|c|c|c|}
\hline & $\begin{array}{l}\text { 3rd } \\
\text { Day }\end{array}$ & $\begin{array}{l}\text { 5th } \\
\text { Day }\end{array}$ & $\begin{array}{l}\text { 1st } \\
\text { Week }\end{array}$ & $\begin{array}{l}\text { 2nd } \\
\text { Week }\end{array}$ & $\begin{array}{l}\text { 3rd } \\
\text { Week }\end{array}$ & $\begin{array}{l}\text { 1st } \\
\text { Month }\end{array}$ & $\begin{array}{l}\text { 3rd } \\
\text { Month }\end{array}$ & $\begin{array}{l}\text { 6th } \\
\text { Month }\end{array}$ & $\begin{array}{l}\text { 1st } \\
\text { Year }\end{array}$ & $\begin{array}{l}\text { 2nd } \\
\text { Year }\end{array}$ & $\begin{array}{l}\text { 3rd } \\
\text { Year }\end{array}$ & $\begin{array}{l}\text { 4th } \\
\text { Year }\end{array}$ & $\begin{array}{l}\text { 5th } \\
\text { Year }\end{array}$ \\
\hline \multicolumn{14}{|c|}{ Trough level (mg/dL) } \\
\hline Tacrobell & 8.6 & 6.3 & 6 & 7.6 & 7 & 7.9 & 7.6 & 7 & 6.5 & 6 & 6.1 & 6 & 6.4 \\
\hline Prograf & 6.9 & 5.7 & 5.8 & 7.2 & 6.6 & 7.2 & 6.9 & 6.2 & 6.3 & 6.4 & 6.6 & 5.9 & 5.7 \\
\hline$p$-value & 0.01 & 0.09 & 0.62 & 0.50 & 0.41 & 0.16 & 0.16 & 0.14 & 0.60 & 0.45 & 0.42 & 0.97 & 0.13 \\
\hline \multicolumn{14}{|c|}{ Drug dosage (mg) } \\
\hline Tacrobell & 2.5 & 2.8 & 3.2 & 5.5 & 5.1 & 4.9 & 3.9 & 3.6 & 3.5 & 3.3 & 3.2 & 3.2 & 2.9 \\
\hline Prograf & 2.7 & 3.4 & 4.1 & 5.7 & 5.1 & 4.9 & 3.8 & 3.7 & 3.5 & 3.2 & 3.1 & 2.9 & 2.6 \\
\hline$p$-value & 0.42 & 0.02 & 0.01 & 0.51 & 0.98 & 0.84 & 0.67 & 0.75 & 0.88 & 0.64 & 0.61 & 0.25 & 0.30 \\
\hline
\end{tabular}

Figure I Relationship between drug dose and drug trough levels during the follow-up period after surgery.

in both groups was infection, followed by biliary complication and rejection.

During the postoperative follow-up period, no difference was found in the incidence of overall infection between the groups ( $48.8 \%$ in the TCB group vs $50.6 \%$ in the PGF group, $p=0.818)$. However, the incidence of pneumonia was $5.8 \%$ $(\mathrm{n}=5)$ in the TCB group and $18.5 \%(\mathrm{n}=16)$ in the PGF group and was significantly lower in the TCB group $(p=0.011)$. There was no difference in the incidence of tuberculosis, wound infections, virus infection (herpes zoster and cytomegalovirus), fungal infections, and Pneumocystis carinii pneumonia (Table 4).

Table 2 Incidence of rehospitalization according to the two groups

\begin{tabular}{llll}
\hline & TCB $(\mathbf{n}=\mathbf{8 6})$ & PGF $(\mathbf{n}=\mathbf{8 I})$ & $\mathbf{p}$-value \\
\hline CV (within I year) & $39.1 \pm \mid 4.72$ & $40.3 \pm I 5.30$ & 0.587 \\
CV (up to 5 years) & $40.8 \pm \mid 4.12$ & $4 \mid .3 \pm 14.10$ & 0.824 \\
\hline
\end{tabular}

Note: Data presented as mean \pm SD unless otherwise indicated. Abbreviations: CV, coefficient of variation; PGF, Prograf; TCB, Tacrobell.
No difference was found in the mean GFR between preoperative and postoperative 5 years between each group. However, at 5 years postoperatively, the GFR in the TCB group was $69.2 \mathrm{~mL} / \mathrm{min} / 1.73 \mathrm{~m}^{2}$, which was higher than that in the PGF group $\left(58.9 \mathrm{~mL} / \mathrm{min} / 1.73 \mathrm{~m}^{2}, p=0.030\right)$ (Figure 3$)$. The frequency of CKD stage 3 or higher renal dysfunction was then examined. The incidence of patients aggravated beyond CKD

Table 3 Comparison of rejection episodes in the TCB and PGF groups

\begin{tabular}{llll}
\hline & TCB (n=86) & PGF (n=8I) & p-value \\
\hline Biopsy proven & I5 (I7.4\%) & $24(29.6 \%)$ & 0.063 \\
Moderate rejection & $7(8.1 \%)$ & $18(22.2 \%)$ & 0.039 \\
Mean RAI & $3.60 \pm I .8 I$ & $4.79 \pm I .74$ & 0.048 \\
Clinical rejection & $13(15.1 \%)$ & $3(3.7 \%)$ & 0.012 \\
Rejection (biopsy + clinical) & $28(32.6 \%)$ & $27(33.3 \%)$ & 0.915 \\
Steroid pulse therapy & $8(9.3 \%)$ & $14(17.3 \%)$ & 0.127 \\
Steroid-resistant rejection & 0 & $4(4.9 \%)$ & 0.037 \\
\hline
\end{tabular}

Note: Moderate rejection: RAI $\geq 4$.

Abbreviations: RAl, rejection activity index; PGF, Prograf; TCB, Tacrobell. 


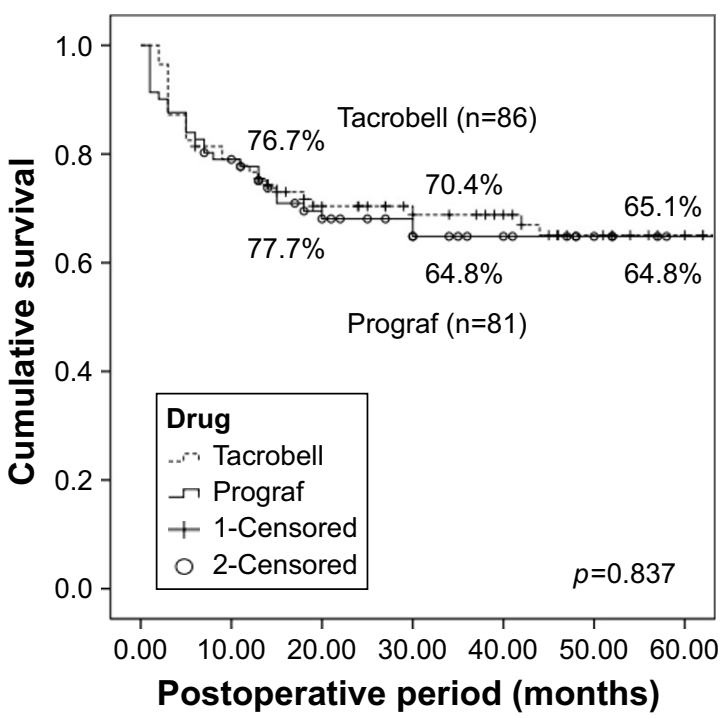

Figure 2 Rejection-free survival in the Tacrobell and Prograf groups.

stage $3\left(\right.$ GFR $\left.<60 \mathrm{~mL} / \mathrm{min} / 1.73 \mathrm{~m}^{2}\right)$ did not differ between the two groups over the entire follow-up period (Table 5).

To compare drug safety, objective signs (hypertension, diabetes, hypercholesterolemia, and de novo neoplasm) and subjective symptoms were compared between the groups. There was no difference in the incidence of newly developed hypertension $(p=0.667)$, diabetes $(p=0.353)$, and hypercholesterolemia $(p=0.358)$ in the TCB and PGF groups, and there was also no difference in the incidence of de novo neoplasm ( $p=0.195$ ) (Table 6). Drug side effects occurred in 59 patients $(68.6 \%)$ in the TCB group and in 62 patients (76.5\%) in the PGF group, but the difference was not significant ( $p=0.251)$. Itching $(24.4 \%)$ was the most common adverse drug reaction in the TCB group, while skin rash $(35.8 \%)$ was the most common adverse drug reaction in the PGF group (Table 7).

Table 4 Comparison of infection rates in TCB and PGF groups

\begin{tabular}{|c|c|c|c|}
\hline & TCB $(n=86)$ & PGF $(n=8 I)$ & $p$-value \\
\hline Overall infections & 42 (48.8\%) & $4 \mathrm{I}(50.6 \%)$ & 0.818 \\
\hline Pneumonia & $5(5.8 \%)$ & 15 (I8.5\%) & 0.011 \\
\hline Tuberculosis & $\mathrm{I}(\mathrm{I} .2 \%)$ & $4(4.9 \%)$ & 0.152 \\
\hline Wound infection & $2(2.3 \%)$ & $\mathrm{I}(\mathrm{I} .2 \%)$ & 0.596 \\
\hline Herpes zoster & $13(15.1 \%)$ & $10(12.3 \%)$ & 0.604 \\
\hline Cytomegalovirus & 17 (19.8\%) & 19 (23.5\%) & 0.562 \\
\hline Fungal infection & $6(7 \%)$ & $10(12.3 \%)$ & 0.239 \\
\hline Aspergillus & I (I7\%) & $6(60 \%)$ & \\
\hline Candida & $5(83 \%)$ & $4(40 \%)$ & \\
\hline Pneumocystis carinii & $2(2.3 \%)$ & I (I.2\%) & 0.596 \\
\hline \multicolumn{4}{|l|}{ Pneumonia } \\
\hline Fever, unknown origin & $9(10.5 \%)$ & $5(6.2 \%)$ & 0.317 \\
\hline
\end{tabular}

Abbreviations: PGF, Prograf; TCB, Tacrobell.

\section{Discussion}

This study evaluated the long-term efficacy and safety of TCB, a generic tacrolimus, compared with PGF, the original form of tacrolimus, in patients undergoing adult LT followed up by a single surgeon. A major concern when administering general immunosuppressants is whether bioequivalence determined through single-dose studies in healthy adults is sufficient evidence of therapeutic equivalence in solid organ transplant patients. ${ }^{4,8} \mathrm{Yu}$ et $\mathrm{al}^{9}$ reported that TCB, as generic tacrolimus, can be considered safe and effective in liver transplant patients. However, they used an openlabel, non-comparative study with a short-term follow-up. Because no previous studies had assessed the long-term efficacy and safety of TCB for LT patients, we analyzed our data to compare the long-term efficacy and safety of both TCB and PGF.

Within the first week, TCB tended to result in higher drug trough levels even with low doses. This finding appears to be similar to the results of previous pharmacokinetic studies of TCB in healthy subjects, who tended to have slightly higher drug trough concentrations after administration of TCB ${ }^{10}$ Further studies will be needed to confirm this result. However, we observed no difference in terms of drug dose and drug concentration between the two groups after the first week after surgery. High intra-patient variability of calcineurin inhibitors in the early posttransplantation stage has been related to worse outcomes in both adult and pediatric kidney and liver transplant recipients. ${ }^{11-13}$ To evaluate the intra-patient variability of tacrolimus, we measured CV values in both groups. In our study population, the two groups did not differ in $\mathrm{CV}$ values within the first year $(p=0.587)$ and up to 5 years $(p=0.824)$. Although the severity of rejection was higher in the PGF group, there was no difference in total rejection between the two groups. There was also no difference in RFS between the groups. Biopsy was performed if there was no improvement after conservative treatment, so there may be some bias here. However, bias was minimized because the same criteria were applied to both groups. Together, our results demonstrated that the efficacy of TCB was not inferior to that of the original drug, PGF.

We subsequently evaluated the safety of TCB. During the follow-up period, there was no difference in the rehospitalization rate between the two groups $(p=0.100)$. Additionally, the overall infection rate did not differ between the two groups ( $p=0.818$ ). Although the incidence of pneumonia was higher in the PGF group, there was no difference in terms of other infections. Serum creatinine and GFR were compared between the two groups to observe changes in renal function. 


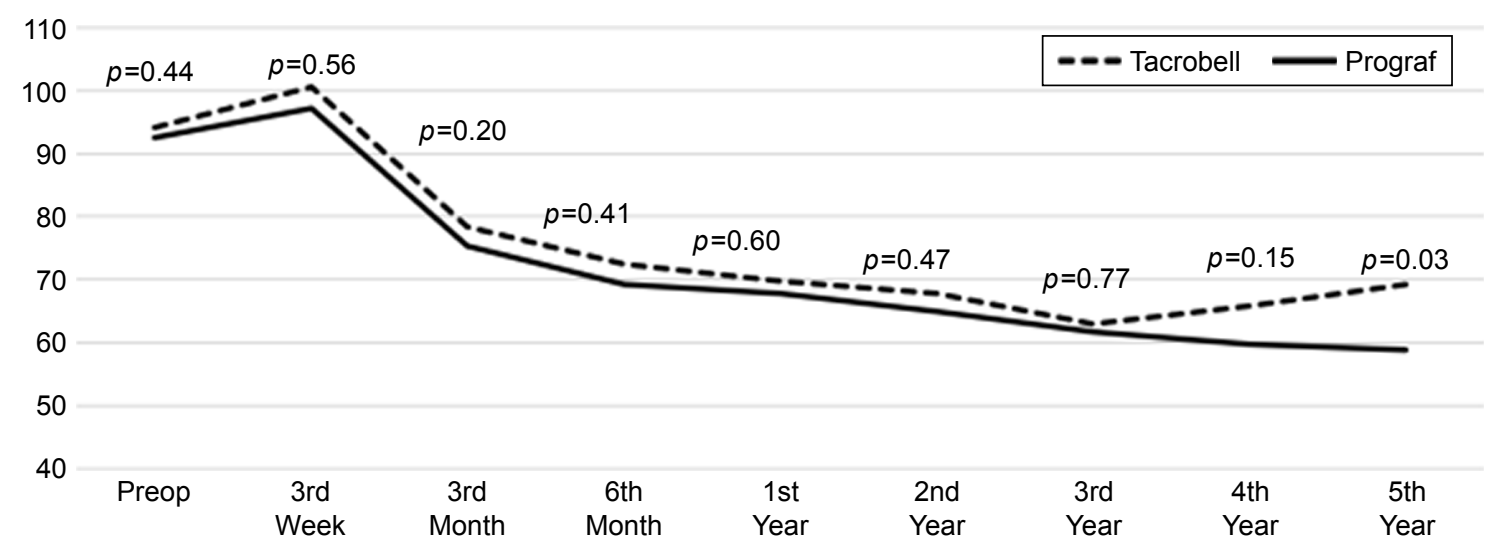

Figure 3 Serial change of the glomerular filtration rate in both groups.

Table 5 Incidence of renal dysfunction (GFR $<60 \mathrm{~mL} / \mathrm{min} / 1.73 \mathrm{~m}^{2}$ ) in both groups

\begin{tabular}{llllllllll}
\hline & Preop & 3rd Week & 3rd Month & 6th Month & Ist Year & 2nd Year & 3rd Year & 4th Year & 5th Year \\
\hline Tacrobell (\%) & 19 & 16 & 23 & 30 & 37 & 45 & 43 & 45 & 33 \\
Prograf (\%) & 26 & 15 & 36 & 37 & 37 & 44 & 37 & 45 & 46 \\
p-value & 0.26 & 0.79 & 0.08 & 0.35 & 0.94 & 0.95 & 0.54 & 0.98 & 0.3 \\
\hline
\end{tabular}

Abbreviations: GFR, glomerular filtration rate; Preop, preoperative.

Table 6 Incidence of new-onset hypertension, diabetes, hypercholesterolemia, and de novo neoplasm

\begin{tabular}{llll}
\hline & TCB (n=86) & PGF (n=8 I) & p-value \\
\hline Hypertension & $26(30.2 \%)$ & $27(33.3 \%)$ & 0.667 \\
Diabetes & $23(26.7 \%)$ & $27(33.3 \%)$ & 0.353 \\
Hypercholesterolemia & $29(33.7 \%)$ & $22(27.2 \%)$ & 0.358 \\
De novo neoplasm & $4(4.7 \%)$ & I (I.2\%) & 0.195 \\
\hline
\end{tabular}

Abbreviations: PGF, Prograf; TCB, Tacrobell.

Table 7 Drug side effects in the two groups

\begin{tabular}{llll}
\hline & TCB (n=86) & PGF (n=8 I) & p-value \\
\hline Overall side effects & $59(68.6 \%)$ & $62(76.5 \%)$ & $0.25 \mathrm{I}$ \\
Headache & $10(11.6 \%)$ & $10(12.3 \%)$ & 0.886 \\
Numbness & $19(22.1 \%)$ & $22(27.2 \%)$ & 0.447 \\
Hair loss & $13(15.1 \%)$ & $17(21.0 \%)$ & 0.323 \\
Itching & $21(24.4 \%)$ & $21(25.9 \%)$ & 0.822 \\
Skin rash & $20(23.3 \%)$ & $29(35.8 \%)$ & 0.075 \\
Diarrhea & $11(12.8 \%)$ & $9(11.1 \%)$ & 0.738 \\
\hline
\end{tabular}

Abbreviations: PGF, Prograf; TCB, Tacrobell.

No difference in GFR was identified between the two groups during the follow-up period, but GFR at 5 years was higher in the TCB group than in the PGF group. Although not statistically significant, the TCB group showed relatively low incidence of renal dysfunction at the 5-year follow-up. However, because of nephrotoxicity, the TCB group is more likely to change or discontinue medication, which is not likely to be significant. This was thought to be due to nephrotoxicity-mediated drug withdrawal in nine patients in the TCB group and five patients in the PGF group. The incidence of new-onset hypertension, diabetes, hypercholesterolemia, and de novo neoplasm did not differ between the groups. Moreover, there was no difference between the two groups in terms of drug side effects. A previous study of kidney transplant patients also found no difference in adverse events (cardiovascular events, cerebrovascular events, malignancies, newly diagnosed onset of diabetes, and infectious events). ${ }^{14}$ These results indicate that TCB is as safe as PGF.

The limitations of this study include the retrospective nature of the work. To assure physicians of the efficacy and safety of a generic immunosuppressant drug, the drug should be validated by prospective, multicenter, large-scale, double-blind, randomized, and long-term clinical trials. ${ }^{15,16}$ However, it is not easy to conduct such an ideal clinical trial with a generic drug. This study only targeted patients who were followed up by one surgeon, so the bias by the investigator was minimized. Therefore, the present study is meaningful because it provides a relatively long-term result, although the study itself is retrospective and the study population is small.

In conclusion, $\mathrm{TCB}$, a generic drug, yielded results similar to those of PGF in various parameters for efficacy and safety. TCB is a comparable alternative to the original tacrolimus as a main immunosuppressive drug. Future prospective 
long-term, multicenter trials are required to support this conclusion.

\section{Acknowledgment}

This study was supported by Chong Kun Dang Pharmaceutical Corp, Seoul, Republic of Korea.

\section{Disclosure}

The authors report no conflicts of interest in this work.

\section{References}

1. US Multicenter FK506 Liver Study Group. A comparison of tacrolimus (FK 506) and cyclosporine for immunosuppression in liver transplantation. N Engl J Med. 1994;331(17):1110-1157.

2. Gu J, Wu X, Lu L, et al. Role of steroid minimization in the tacrolimusbased immunosuppressive regimen for liver transplant recipients: a systematic review and meta-analysis of prospective randomized controlled trials. Hepatol Int. 2014;8(2):198-215.

3. Li XC, Turka LA. An update on regulatory T cells in transplant tolerance and rejection. Nat Rev Nephrol. 2010;6(10):577-583.

4. Molnar AO, Fergusson D, Tsampalieros AK, et al. Generic immunosuppression in solid organ transplantation: systematic review and metaanalysis. BMJ. 2015;350:h3163.

5. Spence MM, Nguyen LM, Hui RL, Chan J. Evaluation of clinical and safety outcomes associated with conversion from brand-name to generic tacrolimus in transplant recipients enrolled in an integrated health care system. Pharmacotherapy. 2012;32(11):981-987.

6. Drug approval information [website on the Internet]. Korea Ministry of Food and Drug Safety [cited July 1, 2016]. Available from: https:// ezdrug.mfds.go.kr. Accessed July 1, 2016.
7. [No authors listed] Banff schema for grading liver allograft rejection: an international consensus document. Hepatology. 1997;25(3):658-663.

8. Harrison JJ, Schiff JR, Coursol CJ, et al. Generic immunosuppression in solid organ transplantation: a Canadian perspective. Transplantation. 2012;93(7):657-665.

9. Yu YD, Lee SG, Joh JW, et al. Results of a phase 4 trial of Tacrobell ${ }^{\mathbb{E}}$ in liver transplantation patients: a multicenter study in South Korea. Hepatogastroenterology. 2012;59(114):357-363.

10. Park KS, Kim YS, Kwon KI, Park MS, Lee YJ, Kim KH. A randomized, open-label, two-period, crossover bioavailability study of two oral formulations of tacrolimus in healthy Korean adults. Clin Ther. 2017; 29(1):154-162.

11. Shemesh E, Fine RN. Is calculating the standard deviation of tacrolimus blood levels the new gold standard for evaluating non-adherence to medications in transplant recipients? Pediatr Transplant. 2010; 14(8):940-943.

12. Borra LC, Roodnat JI, Kal JA, Mathot RA, Weimar W, van Gelder T. High within-patient variability in the clearance of tacrolimus is a risk factor for poor long-term outcome after kidney transplantation. Nephrol Dial Transplant. 2010;25(8):2757-2763.

13. Sapir-Pichhadze R, Wang Y, Famure O, Li Y, Kim SJ. Time-dependent variability in tacrolimus trough blood levels is a risk factor for late kidney transplant failure. Kidney Int. 2014;85(6):1404-1411.

14. Son SY, Jang HR, Lee JE, et al. Comparison of the long-term efficacy and safety of generic Tacrobell with original tacrolimus (Prograf) in kidney transplant recipients. Drug Des Devel Ther. 2017;11:203-210.

15. Alloway RR, Isaacs R, Lake K, et al. Report of the American Society of Transplantation conference on immunosuppressive drugs and the use of generic immunosuppressants. Am J Transplant. 2003;3(10): $1211-1215$

16. Klintmalm GB. Immunosuppression, generic drugs and the FDA. Am J Transplant. 2011;11(9):1765-1766.
Drug Design, Development and Therapy

\section{Publish your work in this journal}

Drug Design, Development and Therapy is an international, peerreviewed open-access journal that spans the spectrum of drug design and development through to clinical applications. Clinical outcomes, patient safety, and programs for the development and effective, safe, and sustained use of medicines are the features of the journal, which

\section{Dovepress}

has also been accepted for indexing on PubMed Central. The manuscript management system is completely online and includes a very quick and fair peer-review system, which is all easy to use. Visit http://www.dovepress.com/testimonials.php to read real quotes from published authors.

Submit your manuscript here: http://www.dovepress.com/drug-design-development-and-therapy-journal 